\title{
High-fat Diet Enhances Mammary Tumorigenesis and Pulmonary Metastasis and Alters Inflammatory and Angiogenic Profiles in MMTV-PyMT Mice
}

\author{
SNEHA SUNDARAM and LIN YAN \\ U.S. Department of Agriculture, Agricultural Research Service, \\ Grand Forks Human Nutrition Research Center, Grand Forks, ND, U.S.A.
}

\begin{abstract}
The MMTV-PyMT transgenic mouse model is commonly used to study luminal B subtype, which has a lower prevalence but a worse prognosis than luminal A subtype among patients with breast cancer. The objective of the present study was to determine whether an obesogenic, high-fat diet enhances primary tumorigenesis and pulmonary metastasis in female MMTV-PyMT mice. The high-fat diet slightly but significantly increased caloric intake and body fat mass compared to the AIN93G diet. The high-fat diet significantly increased primary mammary tumor progression by 59\%, primary tumor weight by $60 \%$, and the number of lung metastases by $147 \%$. Compared to the AIN93G diet, the high-fat diet significantly increased the abundance of proinflammatory cytokines (e.g. leptin, monocyte chemotactic protein-1, plasminogen activator inhibitor-1, resistin, and tumor necrosis factor- $\alpha$ ) and angiogenic factors (e.g. hepatocyte growth factor, tissue inhibitor of metalloproteinase inhibitor-1, and vascular endothelial growth factor) in plasma and mammary tumors. We conclude that the obesogenic high-fat diet enhances primary tumorigenesis and metastasis in MMTV-PyMT mice. This enhancement may be the result of increased proinflammation and angiogenesis signaling.
\end{abstract}

Breast cancer is a heterogeneous disease with several intrinsic subtypes including luminal B breast cancer (1). Luminal B breast cancer is characterized by the expression of estrogen and progesterone receptors and overexpression of human epidermal growth factor receptor 2 and Ki67 (a

This article is freely accessible online.

Correspondence to: Lin Yan, USDA, ARS, Grand Forks Human Nutrition Research Center, 2420 2nd Avenue North, Grand Forks, ND, 58202, U.S.A. Tel: +1 7017958499, Fax: +1 7017958220, email: lin.yan@ars.usda.gov

Key Words: Mammary tumor, metastasis, high-fat diet, MMTVPyMT, mouse model. marker of cell proliferation) (2). Luminal B breast cancer accounts for only $12.4 \%$ of all invasive breast cancers (3). However, it is more aggressive and of a higher grade with a worse prognosis than luminal A breast cancer (4).

Epidemiological studies provide strong evidence that obesity and its associated adipose inflammation are risk factors for breast cancer, including the luminal B subtype (5, $6)$. Being obese at the time of diagnosis of breast cancer can be predictive of poor prognosis $(7,8)$; luminal $\mathrm{B}$ breast cancer is more frequent in obese than in non-obese premenopausal women (9). Weight gain after age 18 years is also strongly associated with the luminal B subtype (10). Furthermore, obese postmenopausal women are at a greater risk of developing luminal B breast cancer $(9,11)$.

The MMTV-PyMT mouse model is commonly used to study luminal B breast cancer. The mouse mammary tumor virus (MMTV) long terminal repeat drives the mammary gland-specific expression of the polyoma virus middle $\mathrm{T}$ antigen (PyMT) and transforms the mammary epithelia, which results in mammary gland tumors (12). The mammary tumorigenesis in this model is characterized by hyperplasia, adenoma, neoplasia, and carcinoma with high incidence of lung metastasis $(12,13)$. Classification and hierarchical clustering analyses suggest that the MMTV-PyMT mammary tumors are similar to those of the luminal subtype (14). Further genetic and marker analyses suggest that MMTVPyMT tumors exhibit the luminal B tumor signature, including short latency and high penetrance $(14,15)$.

Studies using animal models of breast cancer support findings from human studies; obesogenic high-fat diets enhance mammary tumorigenesis in animals (16, 17). Adipose tissue is considered an endocrine organ that produces adipokines (proinflammatory cytokines) which contribute to high-fat diet-enhanced malignant progression $(18,19)$. We hypothesized that obesity-enhanced progression of luminal B breast cancer is through the up-regulation of inflammation. The present study tested this hypothesis by assessing the effects of a high-fat diet on primary mammary 
tumorigenesis and pulmonary metastasis, and alterations in inflammatory and angiogenic profiles in the MMTV-PyMT mouse model.

\section{Materials and Methods}

Animals and diets. Hemizygous female MMTV-PyMT mice were obtained from the in-house breeding colony at Grand Forks Human Nutrition Research Center. The colony was established with FVB/NJ females (stock no: 001800) and hemizygous FVB/NTg(MMTV-PyVT)634Mul/J males (stock no: 002374; The Jackson Laboratory, Bar Harbor, ME, USA). Mice were maintained in a pathogen-free room on a 12:12-hour light/dark cycle with a temperature of $22 \pm 1^{\circ} \mathrm{C}$. Two diets (prepared by the Animal Diet Kitchen at Grand Forks Human Nutrition Research Center) were compared; the AIN93G diet (20) and a modified AIN93G diet, providing $16 \%$ and $45 \%$ (high-fat diet) of energy from soybean oil, respectively (Table I). Both diets were powder diets; they were stored at $-20^{\circ} \mathrm{C}$ until feeding. Gross energy of each diet (Table I) was analyzed by using oxygen bomb calorimetry (Model 6200; Oxygen Bomb Calorimeter, Parr Instrument, Moline, IL, USA).

Experimental design. This study (Y27) was approved by the Institutional Animal Care and Use Committee of the U.S. Department of Agriculture, Agricultural Research Service, Grand Forks Human Nutrition Research Center. The procedures followed the National Institutes of Health Guidelines for the Care and Use of Laboratory Animals (21).

Three-week-old female MMTV-PyMT mice were randomly assigned and weaned onto their respective diets ( $n=33$ per group). Mice had free access to their diets and deionized water and were housed two per cage to avoid stress related to single housing. Food intake was recorded daily ( 5 days per week) for 3 consecutive weeks starting 1 week after the initiation of experimental feeding, and mice were weighed weekly. The duration of experimental feeding was 8 weeks. Body composition of conscious, immobilized mice was performed 1 week before termination by using an EchoMRI whole-body composition analyzer (Model 100; Echo Medical Systems, Houston, TX, USA).

Primary mammary tumorigenesis. Mice were palpated for mammary tumors twice weekly. Tumor latency was defined as the age at which the first palpable mammary tumor was detected (22). Palpable tumors were measured weekly by using a digital caliper (Fred V Fowler Company, Newton, MA, USA). Tumor volume was calculated using the formula: length $\times$ width $^{2} \times 0.5$. Tumor progression as the percentage change in volume over time was calculated using the formula: (end volume - start volume)/start volume $\times 100(22)$.

Lung metastasis. Four weeks after detection of the first palpable mammary tumor, mice were euthanized by an intraperitoneal injection of a mixture of ketamine and xylazine. Lungs were harvested and fixed with Bouin's solution. The number of pulmonary metastases was counted (23) and the cross-sectional area and the volume of each metastasis were analyzed (24) by using ImagePro-Plus software- (Media Cybernetics, Silver Spring, MD, USA) and camera-equipped stereomicroscope. The cross-sectional area was defined as the surface area of each lung metastasis. The volume was estimated using the average diameter of the metastasis with the assumption that metastases were spherical (24). Plasma and mammary tumors were collected and stored at $-80^{\circ} \mathrm{C}$ for further analyses.

Adipokine and angiogenesis profiles. The abundance of adipokines and angiogenic factors in plasma and primary mammary tumors were analyzed by using Proteome Profiler ${ }^{\mathrm{TM}}$ Mouse Adipokine Array (ARY013) and Mouse Angiogenesis Array (ARY015; R\&D Systems, Minneapolis, MN, USA) following the manufacturer's protocols. Primary tumors frozen in liquid nitrogen were pulverized and extracted in radio-immunoprecipitation assay buffer with protease and phosphatase inhibitors (25). Each array was repeated three times with plasma or mammary tumors pooled from four different mice per repetition. Fourteen molecules were included in both arrays; results were reported accordingly in their respective profiles in Table II and Table III. These molecules were dipeptidyl peptidase-4 (DPPIV), fibroblast growth factor-acidic (FGF-acidic), FGF-basic, hepatocyte growth factor (HGF), insulin-like growth factor-binding protein-1 (IGFBP1), IGFBP2, IGFBP3, interleukin10 (IL10), leptin, monocyte chemotactic protein-1 (MCP1), pentraxin, plasminogen activator inhibitor-1 (PAI1), tissue inhibitor of metalloproteinase-1 (TIMP1), and vascular endothelial growth factor (VEGF). The array blots were analyzed by using BioSpectrum 500 Imaging System with LM-26 and BioChemi 500 camera (UVP, Upland, CA, USA), and area densities were measured using VisionWorks ${ }^{\circledR}$ LS Image Acquisition and Analysis Software (Version 8.13; UVP). Results are presented as fold changes in densitometry relative to array background.

Statistical analyses. Student $t$-test was used to compare differences between the groups. Kaplan-Meier analyses were conducted to estimate tumor latency; log-rank and Chi-square tests were used to compare differences between the groups. All data are presented as means \pm standard error of the mean (SEM). Differences with a $p$-value of 0.05 or less were considered significant. All analyses were performed using SAS software (version 9.4; SAS Institute, Cary, NC, USA).

\section{Results}

Body weight, body composition and caloric intake. The highfat diet increased body weight compared to the AIN93G diet (Figure 1A). The difference was significant starting 3 weeks after initiation of the high-fat diet feeding $(p<0.05)$; the increase continued throughout the experiment (Figure 1A). The high-fat diet increased the percentage body fat mass by $17 \%$ compared to the AIN93G diet (Figure 1B). There was no difference in the percentage body lean mass between groups (Figure 1C). The absolute lean mass of mice fed the high-fat diet was $16 \%$ higher than that of mice fed the AIN93G diet (Figure 1D). Caloric intake of mice fed the high-fat diet was $5 \%$ higher than that of mice fed the AIN93G diet (Figure 1E).

Primary mammary tumorigenesis. All mice, regardless of dietary treatments, developed mammary tumors. Feeding mice the high-fat diet increased the latency of mammary tumor; the median latency was 6.0 weeks and 6.1 weeks for 
Table I. Composition of experimental diets.

\begin{tabular}{lcc}
\hline Ingredient & $\begin{array}{c}\text { AIN93G } \\
\mathrm{g} / \mathrm{kg}\end{array}$ & $\begin{array}{c}\text { High-fat } \\
\mathrm{g} / \mathrm{kg}\end{array}$ \\
\hline Corn starch & 397.5 & 42.5 \\
Casein & 200 & 239.4 \\
Dextrin & 132 & 239.4 \\
Sucrose & 100 & 119.7 \\
Soybean oil & 70 & 239.4 \\
Cellulose & 50 & 59.8 \\
AIN93 mineral mix & 35 & 41.9 \\
AIN93 vitamin mix & 10 & 12 \\
L-Cystine & 3 & 3.6 \\
Choline bitartrate & 2.5 & 3 \\
$t$-Butylhydroquinone & 0.014 & 0.017 \\
Total & 1,000 & 1,000 \\
& & \\
Energy & $\%$ & $\%$ \\
Protein & 20 & 20 \\
Fat & 16 & 45 \\
Carbohydrate & 64 & 35 \\
Analyzed gross energy & & \\
kcal/ga & & $5.2 \pm 0.1$ \\
\hline
\end{tabular}

aValues are means \pm SEM of three samples analyzed from each diet.

the AIN93G and the high-fat groups, respectively (hazard ratio $=1.88,95 \%$ confidence interval $=1.40-3.85, p<0.01$; Figure 2A). Tumor progression was defined as the change in tumor volume from detection of the first palpable mammary tumor to termination 4 weeks later. The high-fat diet increased tumor progression by $59 \%$ (Figure 2B) and primary tumor weight by $60 \%$ (Figure $2 \mathrm{C}$ ) compared to the AIN93G diet.

Lung metastasis. There was no significant difference in the incidence of lung metastasis between mice fed the AIN93G diet $(72.7 \%)$ and those fed the high-fat diet $(75.7 \%)$. The high-fat diet significantly increased the number of metastases by $150 \%$ compared to the AIN93G diet (Figure 2D). There were no differences in metastatic cross-sectional area (data not shown) and volume between the groups (Figure 2E). Gross necropsy at termination found no metastatic lesions in other organs.

Adipokine and angiogenesis profiles. Consumption of the high-fat diet altered adipokine and angiogenesis profiles in plasma and primary mammary tumors. The adipokine arrays showed that the high-fat diet compared to the AIN93G diet significantly increased expression of 9 out of the 38 adipokine-related proteins analyzed in plasma and mammary tumors, respectively. These included IGFBP6 in plasma and $\mathrm{C}-\mathrm{C}$ motif chemokine ligand 5 in tumors, and HGF, leptin,
Table II. Adipokine profile (fold-change in densitometry relative to array background) in plasma and mammary tumor of MMTV-PyMT mice fed the AIN93G or the high-fat diet. Mice were weaned onto diets at 3 weeks old and continued on diets until termination 4 weeks following tumor detection (the duration of experimental feeding was 8 weeks). Values are means \pm SEM $(n=3)$.

\begin{tabular}{|c|c|c|c|c|}
\hline \multirow[b]{2}{*}{ Adipokine } & \multicolumn{2}{|c|}{ Plasma } & \multicolumn{2}{|c|}{ Mammary tumor } \\
\hline & AIN93G & High-fat & AIN93G & High-fat \\
\hline Adiponectin & $9.7 \pm 1.0$ & $6.1 \pm 0.6^{*}$ & $40.1 \pm 2.5$ & $25.7 \pm 2.1 *$ \\
\hline AgRP & $1.3 \pm 0.01$ & $1.1 \pm 0.01 *$ & $1.5 \pm 0.1$ & $1.6 \pm 0.2$ \\
\hline ANGPTL3 & $5.2 \pm 0.7$ & $5.1 \pm 1.0$ & $1.6 \pm 0.04$ & $1.7 \pm 0.1$ \\
\hline C-Reactive protein & $6.8 \pm 0.5$ & $8.5 \pm 1.0$ & $21.5 \pm 0.5$ & $13.5 \pm 0.5 *$ \\
\hline DPPIV & $9.2 \pm 1.3$ & $12.7 \pm 1.4$ & $8.4 \pm 1.0$ & $5.4 \pm 0.5$ \\
\hline Endocan & $2.9 \pm 1.0$ & $4.3 \pm 1.5$ & $3.5 \pm 0.6$ & $5.2 \pm 0.3$ \\
\hline FetuinA & $1.6 \pm 0.1$ & $1.9 \pm 0.2$ & $5.5 \pm 0.6$ & $3.5 \pm 0.6$ \\
\hline FGF-acidic & $1.0 \pm 0.02$ & $1.0 \pm 0.01$ & $5.5 \pm 0.5$ & $5.3 \pm 0.9$ \\
\hline FGF21 & $5.6 \pm 3.0$ & $5.6 \pm 2.8$ & $1.2 \pm 0.1$ & $1.4 \pm 0.1$ \\
\hline $\mathrm{HGF}$ & $1.0 \pm 0.01$ & $1.8 \pm 0.1 *$ & $1.3 \pm 0.1$ & $1.6 \pm 0.1^{*}$ \\
\hline ICAM1 & $2.6 \pm 0.5$ & $3.7 \pm 0.7$ & $7.3 \pm 0.4$ & $4.7 \pm 0.4^{*}$ \\
\hline IGF1 & $1.6 \pm 0.2$ & $2.5 \pm 0.2$ & $1.5 \pm 0.01$ & $1.3 \pm 0.1$ \\
\hline IGF2 & $1.2 \pm 0.01$ & $1.3 \pm 0.1$ & $2.3 \pm 0.04$ & $1.7 \pm 0.1 *$ \\
\hline IGFBP1 & $12.8 \pm 3.6$ & $19.5 \pm 5.6$ & $4.8 \pm 1.1$ & $7.8 \pm 0.9$ \\
\hline IGFBP2 & $9.3 \pm 1.0$ & $10.2 \pm 1.2$ & $9.6 \pm 1.6$ & $9.6 \pm 0.9$ \\
\hline IGFBP3 & $11.8 \pm 1.6$ & $14.7 \pm 1.6$ & $17.2 \pm 1.0$ & $12.4 \pm 1.1^{*}$ \\
\hline IGFBP5 & $5.4 \pm 0.4$ & $6.3 \pm 0.7$ & $7.0 \pm 0.4$ & $5.0 \pm 0.4^{*}$ \\
\hline IGFBP6 & $14.4 \pm 0.8$ & $18.8 \pm 1.1 *$ & $10.5 \pm 1.1$ & $6.2 \pm 0.6^{*}$ \\
\hline IL6 & $1.0 \pm 0.02$ & $1.0 \pm 0.02$ & $1.2 \pm 0.1$ & $1.4 \pm 0.1$ \\
\hline IL10 & $1.0 \pm 0.03$ & $1.0 \pm 0.01$ & $1.2 \pm 0.1$ & $1.4 \pm 0.1$ \\
\hline IL11 & $1.1 \pm 0.10$ & $1.1 \pm 0.1$ & $1.4 \pm 0.1$ & $1.4 \pm 0.1$ \\
\hline Leptin & $1.2 \pm 0.04$ & $1.9 \pm 0.1 *$ & $1.5 \pm 0.04$ & $2.9 \pm 0.1 *$ \\
\hline LIF & $1.0 \pm 0.06$ & $1.0 \pm 0.04$ & $1.9 \pm 0.2$ & $2.5 \pm 0.1$ \\
\hline Lipcalin2 & $2.9 \pm 0.53$ & $4.0 \pm 0.5$ & $2.2 \pm 0.2$ & $1.5 \pm 0.1$ \\
\hline MCP1 & $1.1 \pm 0.04$ & $2.4 \pm 0.2 *$ & $2.8 \pm 0.6$ & $5.4 \pm 0.3^{*}$ \\
\hline $\mathrm{M}-\mathrm{CSF}$ & $4.3 \pm 0.5$ & $5.6 \pm 0.8$ & $8.7 \pm 0.5$ & $5.5 \pm 0.3$ \\
\hline OncostatinM & $1.1 \pm 0.02$ & $1.1 \pm 0.02$ & $1.4 \pm 0.1$ & $1.5 \pm 0.1$ \\
\hline Pentraxin 2 & $2.3 \pm 0.1$ & $2.5 \pm 0.1$ & $2.7 \pm 0.2$ & $2.4 \pm 0.2$ \\
\hline Pentraxin 3 & $2.2 \pm 0.7$ & $3.0 \pm 1.3$ & $5.4 \pm 0.5$ & $3.3 \pm 0.2 *$ \\
\hline PREF1 & $1.4 \pm 0.2$ & $1.7 \pm 0.4$ & $1.5 \pm 0.03$ & $1.3 \pm 0.1$ \\
\hline RAGE & $1.2 \pm 0.1$ & $1.1 \pm 0.1$ & $1.2 \pm 0.05$ & $1.3 \pm 0.1$ \\
\hline RANTES & $1.0 \pm 0.04$ & $1.1 \pm 0.1$ & $1.5 \pm 0.1$ & $2.2 \pm 0.1^{*}$ \\
\hline $\mathrm{RBP} 4$ & $1.3 \pm 0.10$ & $1.5 \pm 0.2$ & $3.9 \pm 0.2$ & $3.1 \pm 0.2$ \\
\hline Resistin & $25.2 \pm 2.8$ & $41.3 \pm 4.0^{*}$ & $22.6 \pm 3.7$ & $35.5 \pm 1.2 *$ \\
\hline PAI1 & $2.1 \pm 0.10$ & $4.3 \pm 0.7 *$ & $11.1 \pm 2.2$ & $23.4 \pm 1.0 *$ \\
\hline TIMP1 & $1.4 \pm 0.3$ & $3.2 \pm 0.5^{*}$ & $4.2 \pm 1.2$ & $10.5 \pm 0.5 *$ \\
\hline $\mathrm{TNF} \alpha$ & $1.0 \pm 0.1$ & $1.4 \pm 0.02 *$ & $1.1 \pm 0.03$ & $1.5 \pm 0.1^{*}$ \\
\hline VEGF & $1.2 \pm 0.1$ & $1.6 \pm 0.1^{*}$ & $4.2 \pm 1.3$ & $9.2 \pm 0.9^{*}$ \\
\hline
\end{tabular}

*Significantly different at $p<0.05$ compared to the AIN93G diet. AgRP: Agouti-related protein; ANGPTL3: angiopoietin-like 3; DPPIV: dipeptidyl peptidase-4; FGF: fibroblast growth factor; HGF: hepatocyte growth factor; ICAM: intercellular adhesion molecule; IGF: insulin-like growth factor; IGFBP: insulin-like growth factor-binding protein; IL: interleukin; LIF: leukemia-inhibiting factor; MCP1: monocyte chemotactic protein-1; M-CSF: macrophage colony-stimulating factor; PREF1: preadipocyte factor-1; RAGE: receptor for advanced glycation end-products; RANTES: C-C motif chemokine ligand 5 or regulated on activation, normal T-cell expressed and secreted; RBP: retinol-binding protein; PAI1: plasminogen activator inhibitor-1; TIMP: tissue inhibitor of metalloproteinases; TNF $\alpha$ : tumor necrosis factor- $\alpha$; VEGF: vascular endothelial growth factor. 
Table III. Angiogenesis profile (fold-change in densitometry relative to array background) in plasma and mammary tumor of MMTV-PyMT mice fed the AIN93G or the high-fat diet. Mice were weaned onto diets at 3 weeks old and continued on diets until termination 4 weeks following tumor detection (the duration of experimental feeding was 8 weeks). Values are means $\pm \operatorname{SEM}(n=3)$.

\begin{tabular}{|c|c|c|c|c|}
\hline \multirow[b]{2}{*}{ Angiogenic molecule } & \multicolumn{2}{|c|}{ Plasma } & \multicolumn{2}{|c|}{ Mammary tumor } \\
\hline & AIN93G & High-fat & AIN93G & High-fat \\
\hline ADAMTS1 & $1.2 \pm 0.2$ & $2.3 \pm 0.4 *$ & $2.3 \pm 0.1$ & $3.0 \pm 0.1 *$ \\
\hline Amphiregulin & $1.7 \pm 0.2$ & $1.3 \pm 0.1 *$ & $2.6 \pm 0.2$ & $2.5 \pm 0.3$ \\
\hline Angiogenin & $5.7 \pm 1.2$ & $4.9 \pm 1.2$ & $3.4 \pm 0.4$ & $3.7 \pm 0.4$ \\
\hline Angiopoietin 1 & $5.7 \pm 2.0$ & $10.9 \pm 4.1$ & $13.4 \pm 1.3$ & $20.0 \pm 1.7$ \\
\hline Angiopoietin 3 & $1.8 \pm 0.2$ & $1.8 \pm 0.3$ & $1.6 \pm 0.01$ & $1.8 \pm 0.1 *$ \\
\hline Coagulation factor III & $1.6 \pm 0.2$ & $2.4 \pm 0.3$ & $10.6 \pm 1.6$ & $8.0 \pm 0.6$ \\
\hline CXCL16 & $10.4 \pm 2.9$ & $12.9 \pm 3.2$ & $5.3 \pm 0.8$ & $7.0 \pm 0.7$ \\
\hline Cyr61 & $3.8 \pm 1.0$ & $6.4 \pm 1.1$ & $9.4 \pm 0.8$ & $11.6 \pm 0.8$ \\
\hline DLL4 & $1.7 \pm 0.2$ & $2.06 \pm 0.4$ & $2.2 \pm 0.2$ & $2.7 \pm 0.2$ \\
\hline DPPIV & $11.0 \pm 1.7$ & $10.8 \pm 1.5$ & $7.2 \pm 1.4$ & $7.3 \pm 1.2$ \\
\hline EGF & $1.6 \pm 0.1$ & $1.2 \pm 0.05^{*}$ & $26.0 \pm 5.0$ & $7.3 \pm 1.9^{*}$ \\
\hline Endoglin & $2.0 \pm 0.3$ & $3.2 \pm 0.03 *$ & $3.6 \pm 0.5$ & $4.0 \pm 0.3$ \\
\hline Endostatin/collagen XVIII & $12.3 \pm 0.7$ & $13.5 \pm 0.6$ & $10.6 \pm 1.6$ & $7.7 \pm 0.9$ \\
\hline Endothelin1 & $2.5 \pm 0.3$ & $2.1 \pm 0.4$ & $2.7 \pm 0.3$ & $3.1 \pm 0.1$ \\
\hline FGF-acidic & $3.1 \pm 0.2$ & $2.2 \pm 0.3 *$ & $4.3 \pm 0.9$ & $4.7 \pm 0.7$ \\
\hline FGF-basic & $2.0 \pm 0.3$ & $2.0 \pm 0.3$ & $3.2 \pm 0.1$ & $2.6 \pm 0.2 *$ \\
\hline KGF & $2.0 \pm 0.4$ & $1.6 \pm 0.3$ & $1.5 \pm 0.1$ & $1.8 \pm 0.1$ \\
\hline Fractalkine & $4.7 \pm 1.4$ & $3.9 \pm 1.1$ & $4.0 \pm 0.2$ & $5.7 \pm 0.5^{*}$ \\
\hline GM-CSF & $1.9 \pm 0.3$ & $1.4 \pm 0.1$ & $1.4 \pm 0.2$ & $1.7 \pm 0.2$ \\
\hline HB-EGF & $1.5 \pm 0.2$ & $1.3 \pm 0.1$ & $2.3 \pm 0.4$ & $1.9 \pm 0.2$ \\
\hline HGF & $1.8 \pm 0.3$ & $4.1 \pm 0.3^{*}$ & $3.3 \pm 0.2$ & $4.4 \pm 0.3 *$ \\
\hline IGFBP1 & $24.0 \pm 1.4$ & $33.2 \pm 1.5^{*}$ & $4.0 \pm 0.4$ & $8.0 \pm 1.3$ \\
\hline IGFBP2 & $24.4 \pm 1.0$ & $16.5 \pm 0.3^{*}$ & $13.1 \pm 2.1$ & $15.7 \pm 2.2$ \\
\hline IGFBP3 & $26.9 \pm 3.1$ & $23.8 \pm 1.2$ & $15.7 \pm 2.3$ & $20.2 \pm 2.0$ \\
\hline $\operatorname{IL} 1 \alpha$ & $1.4 \pm 0.1$ & $1.2 \pm 0.03 *$ & $2.0 \pm 0.1$ & $3.3 \pm 0.2 *$ \\
\hline IL1B & $1.8 \pm 0.2$ & $1.6 \pm 0.2$ & $1.2 \pm 0.01$ & $1.7 \pm 0.1 *$ \\
\hline IL10 & $1.9 \pm 0.4$ & $1.6 \pm 0.2$ & $1.6 \pm 0.04$ & $1.6 \pm 0.02$ \\
\hline IP10 & $1.8 \pm 0.3$ & $1.6 \pm 0.3$ & $1.5 \pm 0.09$ & $1.6 \pm 0.03$ \\
\hline $\mathrm{KC}$ & $2.3 \pm 0.5$ & $2.0 \pm 0.4$ & $6.0 \pm 0.4$ & $10.0 \pm 0.7 *$ \\
\hline Leptin & $1.9 \pm 0.3$ & $3.6 \pm 0.4 *$ & $1.6 \pm 0.1$ & $2.4 \pm 0.2 *$ \\
\hline MCP1 & $1.8 \pm 0.3$ & $3.2 \pm 0.2 *$ & $4.8 \pm 0.2$ & $7.9 \pm 0.7 *$ \\
\hline MIP1a & $2.9 \pm 0.4$ & $2.2 \pm 0.3$ & $1.8 \pm 0.1$ & $2.1 \pm 0.2$ \\
\hline MMP3 & $29.0 \pm 2.4$ & $38.5 \pm 2.1^{*}$ & $17.2 \pm 1.5$ & $12.5 \pm 1.0$ \\
\hline MMP8 & $5.2 \pm 1.6$ & $6.0 \pm 1.6$ & $1.6 \pm 0.1$ & $1.9 \pm 0.1$ \\
\hline MMP9 & $12.5 \pm 2.5$ & $16.6 \pm 3.4$ & $8.0 \pm 1.5$ & $11.6 \pm 1.8$ \\
\hline NOV & $28.1 \pm 1.8$ & $34.9 \pm 2.1 *$ & $5.3 \pm 0.5$ & $9.0 \pm 0.8^{*}$ \\
\hline Osteopontin & $11.4 \pm 1.0$ & $8.0 \pm 0.4^{*}$ & $2.9 \pm 0.5$ & $2.6 \pm 0.2$ \\
\hline PD-ECGF & $1.5 \pm 0.2$ & $1.5 \pm 0.2$ & $1.5 \pm 0.1$ & $1.7 \pm 0.2$ \\
\hline PDGFAA & $2.0 \pm 0.4$ & $2.9 \pm 0.9$ & $4.0 \pm 0.3$ & $5.1 \pm 0.2^{*}$ \\
\hline PDGFAB/BB & $2.4 \pm 0.7$ & $2.9 \pm 0.9$ & $2.6 \pm 0.1$ & $3.0 \pm 0.2$ \\
\hline Pentraxin & $5.3 \pm 1.1$ & $5.7 \pm 1.5$ & $5.5 \pm 0.7$ & $6.7 \pm 0.6$ \\
\hline Platelet factor4 & $23.8 \pm 0.2$ & $18.4 \pm 1.3^{*}$ & $12.0 \pm 1.2$ & $14.1 \pm 1.5$ \\
\hline PLGF2 & $5.2 \pm 1.4$ & $7.2 \pm 1.5$ & $20.5 \pm 2.7$ & $24.9 \pm 2.6$ \\
\hline Prolactin & $5.8 \pm 1.4$ & $5.1 \pm 1.4$ & $1.5 \pm 0.1$ & $1.7 \pm 0.1$ \\
\hline Proliferin & $1.9 \pm 0.3$ & $2.3 \pm 0.4$ & $1.5 \pm 0.1$ & $1.8 \pm 0.1$ \\
\hline SDF1 & $13.3 \pm 3.8$ & $19.3 \pm 5.2$ & $3.5 \pm 0.4$ & $4.6 \pm 0.4$ \\
\hline PAI1 & $13.3 \pm 3.4$ & $26.4 \pm 4.1 *$ & $22.0 \pm 2.7$ & $31.2 \pm 0.9 *$ \\
\hline SerpinF1 & $6.3 \pm 1.8$ & $8.0 \pm 2.3$ & $11.7 \pm 2.1$ & $14.3 \pm 1.6$ \\
\hline Thrombospondin 2 & $2.1 \pm 0.4$ & $4.2 \pm 0.7 *$ & $4.4 \pm 0.2$ & $6.0 \pm 0.1 *$ \\
\hline TIMP1 & $2.1 \pm 0.4$ & $3.9 \pm 0.6^{*}$ & $2.7 \pm 0.1$ & $3.6 \pm 0.1 *$ \\
\hline TIMP4 & $6.4 \pm 2.0$ & $5.4 \pm 1.7$ & $1.4 \pm 0.1$ & $1.5 \pm 0.03$ \\
\hline VEGF & $1.2 \pm 0.1$ & $2.5 \pm 0.2 *$ & $1.2 \pm 0.1$ & $1.7 \pm 0.1^{*}$ \\
\hline VEGFB & $1.8 \pm 0.2$ & $1.6 \pm 0.3$ & $1.8 \pm 0.1$ & $2.0 \pm 0.1$ \\
\hline
\end{tabular}

*Significantly different at $p<0.05$ compared to the AIN93G diet. ADAMTS1: A disintegrin and metalloproteinase with thrombospondin motifs 1; CXCL16: C-X-C motif chemokine ligand-16; Cyr61: cysteine-rich angiogenic inducer-61; DLL4: delta-like ligand-4; DPPIV: dipeptidyl peptidase-4; EGF: epidermal growth factor; FGF: fibroblast growth factor; KGF: keratinocyte growth factor; GM-CSF: granulocyte-macrophage colony-stimulating factor; HB-EGF: heparin-binding EGF-like growth factor; HGF: hepatocyte growth factor; IGFBP: insulin-like growth factor-binding protein; IL: interleukin; IP: interferon gamma-induced protein; KC: keratinocyte-derived CXC motif; MCP1: monocyte chemotactic protein 1; MIP: macrophage inflammatory protein; MMP: matrix metalloproteinase; NOV: nephroblastoma overexpressed; PD-ECGF: platelet-derived endothelial cell growth factor; PDGF: platelet-derived growth factor; PLGF2: placental growth factor-2; SDF1: stromal cell-derived factor-1; PAI1: plasminogen activator inhibitor1; serpinF1: Pigment epithelium-derived factor; TIMP: tissue inhibitor of metalloproteinases; VEGF: vascular endothelial growth factor. 

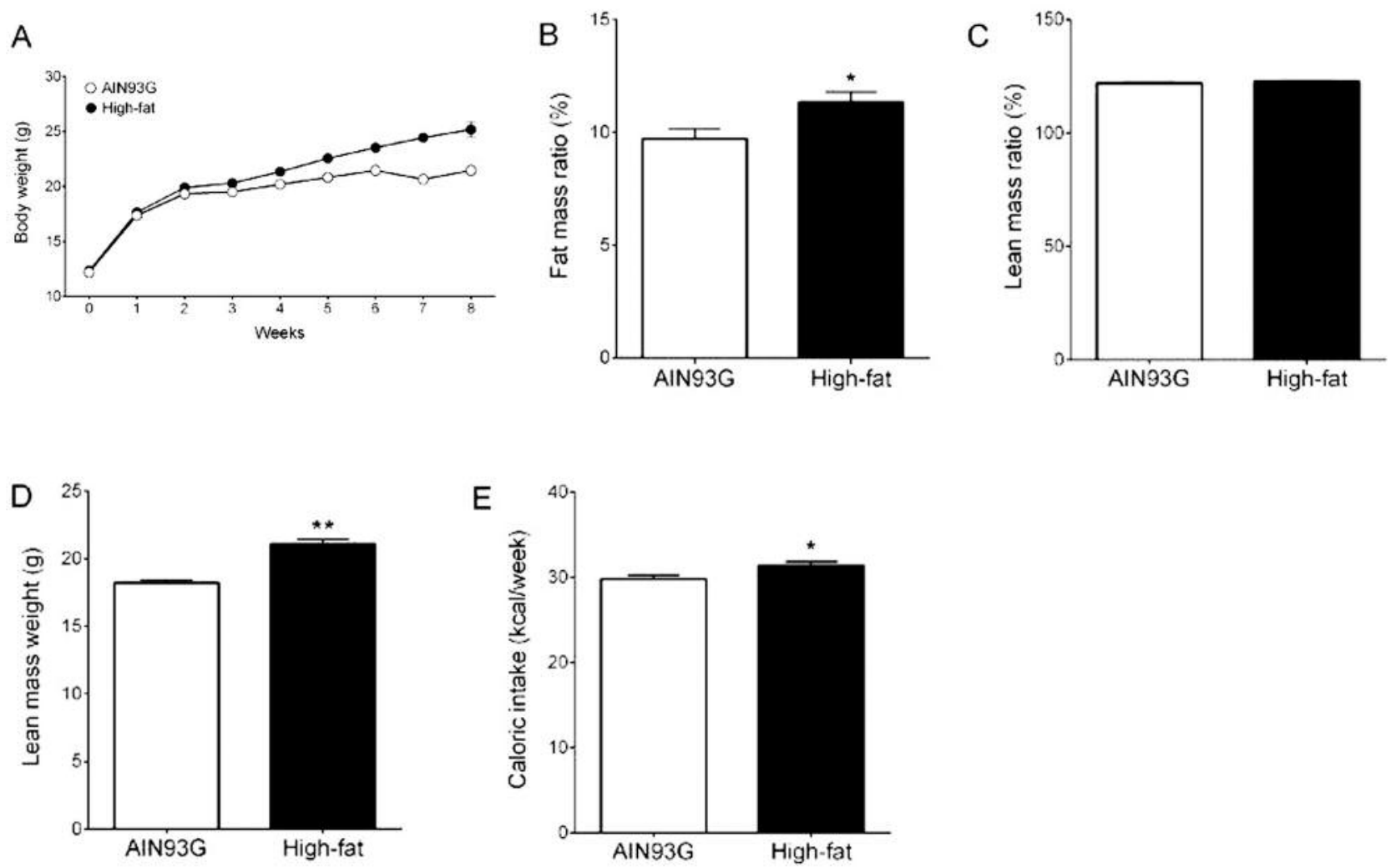

Figure 1. Body weight $(A)$, body fat mass ratio $(B)$, lean mass ratio $(C)$, lean mass weight $(D)$, and caloric intake $(E)$ of $M M T V-P y M T$ mice fed the AIN93G or the high-fat diet. Mice fed the high-fat diet were heavier than those fed the AIN93G diet, the difference being significant from 3 weeks after the initiation of experimental feeding $(p<0.05)$; the significant increase continued throughout the experiment. The measurement unit of caloric intake was from two mice per cage. Values are means \pm SEM ( $n=33$ per group for $A, B, C, D ; n=6$ per group for E). Significantly different compared to the AIN $93 G$ diet at $* p<0.05$, and $* * p<0.01$.

MCP1, resistin, PAI1, TIMP1, tumor necrosis factor- $\alpha$ (TNF $\alpha$ ), and VEGF in both plasma and tumors (Table II). The high-fat diet significantly reduced adiponectin and agouti-related protein in plasma and 8 out of the 38 adipokine-related proteins assayed in tumors [adiponectin, C-reactive protein, intercellular adhesion molecule-1, insulin-like growth factor-II (IGF-II), IGFBP3, IGFBP5, IGFBP6, and pentraxin-3] (Table II). The angiogenesis arrays showed that out of the 53 angiogenesis-related proteins analyzed the high-fat diet significantly increased expression of 12 and 15 proteins in plasma and mammary tumors, respectively. These included endoglin, IGFBP1, and matrix metalloproteinase-3 in plasma and angiopoietin-3, fractalkine, IL1 $\alpha$, IL1 $\beta$, keratinocyte-derived chemokine, and platelet derived growth factor-AA in tumors, and a disintegrin and metallopeptidase with thrombospondin type 1 motif 1, HGF, leptin, MCP1, nephroblastoma overexpressed, PAI1, thorombospondin-2, TIMP1, and VEGF in both plasma and tumors (Table III). The high-fat diet significantly reduced seven out of the 53 angiogenesisrelated proteins assayed in plasma [amphiregulin, epidermal growth factor (EGF), FGF-acidic, IGFBP2, IL1 $\alpha$, osteopontin, and platelet factor-4] and two in tumors (EGF and FGF-basic) (Table III).

More importantly, results of the adipokine arrays showed that the high-fat diet compared to the AIN93G diet increased plasma abundance of HGF by $83 \%$, leptin by $61 \%$, MCP1 by $115 \%$, resistin by $64 \%$, PAI 1 by $107 \%$, TIMP 1 by $138 \%$, TNF $\alpha$ by $31 \%$, and VEGF by $31 \%$, and reduced plasma adiponectin by $37 \%$ (Table II). The mammary tumor analysis exhibited similar findings (Table II). Similar results were obtained from the angiogenesis arrays (Table III).

\section{Discussion}

The present study showed that an obesogenic high-fat diet increases the growth of primary mammary tumors and the number of metastases formed in the lungs. This indicates 

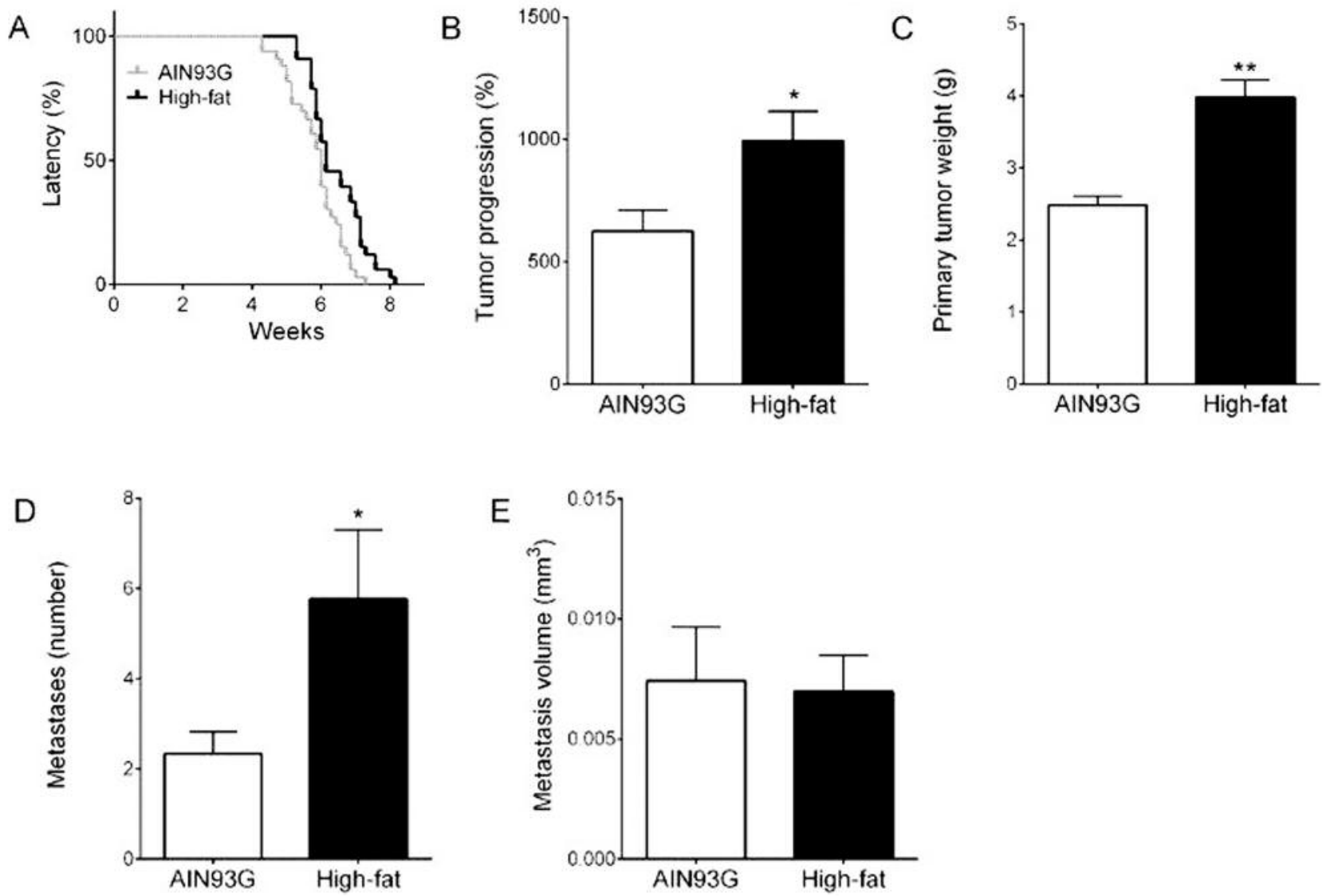

Figure 2. Tumor latency $(A)$, tumor progression $(B)$, and weight $(C)$ of primary mammary tumors, and number $(D)$ and volume $(E)$ of lung metastases in MMTV-PyMT mice fed the AIN93G or the high-fat diet. The median latency was 6.0 and 6.1 weeks for the AIN93G and the high-fat diet-fed groups, respectively (hazard ratio $=1.88,95 \%$ confidence interval $=1.40-3.85, p<0.01)(A)$. Values are means \pm SEM ( $n=33$ per group). Significantly different compared to the AIN $93 G$ diet at $* p<0.05$, and $* * p<0.01$.

that an obesogenic diet enhances malignant progression in this MMTV-PyMT mouse model of luminal B breast cancer.

Proinflammatory cytokines, which can be produced in increased amounts under pathophysiological conditions, participate in cancer development and progression. Our findings of a significant increase in the abundance of proinflammatory cytokines, including MCP1, PAI1, TNF $\alpha$, and resistin, in plasma and mammary tumors by the highfat diet indicate that increased proinflammatory cytokines exacerbate mammary tumorigenesis and pulmonary metastasis in MMTV-PyMT mice. Similarly, previous studies showed that proinflammatory cytokines, e.g. MCP1 and PAI1, are found in plasma and mammary tumors from MMTV-PyMT mice (26-28). Expression of proinflammatory cytokines MCP1 (26), PAI1 (29, 30), $\mathrm{TNF} \alpha$ (31), and resistin (32) are elevated in invasive breast cancer. In luminal B breast cancer, increased the expression of these cytokines is associated with poor prognosis and lower overall survival $(26,33,34)$. Findings from the present study are further supported by our previous reports that MCP1 (18) and PAI1 (19) contribute to enhanced spontaneous metastasis of Lewis lung carcinoma in mice fed a high-fat diet.

Angiogenesis plays important roles in tumorigenesis and in transporting malignant cells to distant organs to form metastases. The high-fat diet significantly increased the content of potent angiogenic factors including HGF, VEGF, and TIMP1 in plasma and primary tumors, indicating an upregulation of angiogenesis. Overexpression of $\mathrm{HGF}$ in mammary glands resulted in highly aggressive tumors with lung metastases (35). Elevated expressions of HGF (36), VEGF (37), and TIMP1 (38) in invasive breast cancer contribute to poor survival outcomes in breast cancer patients. In MMTV-PyMT mice, overexpression of VEGF leads to increased metastasis (39), the increase being through VEGF- 
enhanced angiogenesis and sustained tumor proliferation and survival (39). The expression of TIMPl mRNA is significantly increased in malignant breast tissues (40), and the expression increases gradually with the invasive potential of carcinoma cells (38). Thus, our findings are consistent with existing knowledge of the roles of angiogenic factors in mammary tumorigenesis. This suggests that the up-regulation of angiogenesis by the high-fat diet may contribute to exacerbated tumorigenesis and metastasis in the MMTVPyMT model.

Increased leptin and lower adiponectin concentration in plasma and mammary tumors of mice fed the high-fat diet were likely the result of increased adiposity. Physiological functions of leptin and adiponectin are to regulate energy metabolism $(41,42)$. However, studies also show that they can participate in carcinogenesis. An elevated plasma concentration of leptin is associated with an increased risk of breast cancer with advanced lesions (43). Adiponectin is anti-inflammatory; low circulating adiponectin levels are associated with increased breast cancer risk $(44,45)$. In MMTV-PyMT mice, inhibition of leptin signaling by depletion of leptin receptors inhibits tumor progression and metastasis (46), and adiponectin insufficiency facilitates mammary tumorigenesis (47). The dichotomy of leptin and adiponectin effects contribute to the pathophysiology of breast cancer (48). Thus, our results indicate that a high-fat diet alters energy metabolism such that it contributes to the exacerbated tumorigenesis and metastasis exhibited by MMTV-PyMT mice.

Our results that the high-fat diet prolonged primary tumor latency do not agree with reports that a high-fat diet shortens or does not affect primary tumor latency $(28,49)$. This disagreement may be caused by experimental differences, $e . g$. animal models used (49), or methods to assess the latency (28). Nevertheless, the prolonged latency did not attenuate the tumorigenic enhancement by the high-fat diet, evidenced by the increased primary tumor burden and lung metastases.

In summary, our findings show that an obesogenic diet increases primary mammary tumorigenesis and lung metastasis in MMTV-PyMT mice. The increased aggressiveness of mammary carcinogenesis by the high-fat diet may be the result of up-regulation of proinflammatory and angiogenic signaling. Lifestyle changes such as reducing excessive caloric intake or increasing energy expenditure reduce body adiposity and associated inflammation (50). The fact that these lifestyle changes may attenuate obesitymediated breast cancer risk, including luminal B breast cancer, warrants further investigation.

\section{Conflicts of Interest}

The Authors declare that they have no conflict of interest in regards to this study.

\section{Acknowledgements}

The Authors greatly acknowledge the assistance of the following staff of Grand Forks Human Nutrition Research Center: Lana DeMars and Kay Keehr for technical support, LuAnn Johnson for statistical analysis, Dr. Forrest Nielsen for providing helpful input in manuscript preparation, James Lindlauf for preparing experimental diets and vivarium staff for providing high quality animal care. Funding for this work was provided by the U.S. Department of Agriculture, ARS, Research project: 5450-51000-045-00D. The U.S. Department of Agriculture, Agricultural Research Service, Plains Area is an equal opportunity/affirmative action employer and all agency services are available without discrimination. Mention of trade names or commercial products in this article is solely for providing specific information and does not imply recommendation or endorsement by the U.S. Department of Agriculture.

\section{References}

1 Perou CM, Sorlie T, Eisen MB, van de Rijn M, Jeffrey SS, Rees CA, Pollack JR, Ross DT, Johnsen H, Akslen LA, Fluge O, Pergamenschikov A, Williams C, Zhu SX, Lonning PE, Borresen-Dale AL, Brown PO and Botstein D: Molecular portraits of human breast tumours. Nature 406: 747-752, 2000.

2 American Cancer Society: Breast Cancer Facts \& Figures 20152016. Atlanta: American Cancer Society, Inc. 2015.

3 Kohler BA, Sherman RL, Howlader N, Jemal A, Ryerson AB, Henry KA, Boscoe FP, Cronin KA, Lake A, Noone AM, Henley SJ, Eheman CR, Anderson RN and Penberthy L: Annual Report to the Nation on the Status of Cancer, 1975-2011, Featuring Incidence of Breast Cancer Subtypes by Race/Ethnicity, Poverty, and State. J Natl Cancer Inst 107: djv048, 2015.

4 Parise CA and Caggiano V: Breast cancer survival defined by the ER/PR/HER2 subtypes and a surrogate classification according to tumor grade and immunohistochemical biomarkers. J Cancer Epidemiol 2014: 469251, 2014.

5 Calle EE, Rodriguez C, Walker-Thurmond $\mathrm{K}$ and Thun MJ: Overweight, obesity, and mortality from cancer in a prospectively studied cohort of U.S. adults. New Eng J Med 348: 1625-1638, 2003.

6 Rohan TE, Heo M, Choi L, Datta M, Freudenheim JL, Kamensky V, Ochs-Balcom HM, Qi L, Thomson CA, Vitolins MZ, Wassertheil-Smoller S and Kabat GC: Body fat and breast cancer risk in postmenopausal women: a longitudinal study. J Cancer Epidemiol 2013: 754815, 2013.

7 Carmichael AR: Obesity and prognosis of breast cancer. Obes Rev 7: 333-340, 2006.

8 Loi S, Milne RL, Friedlander ML, McCredie MR, Giles GG, Hopper JL and Phillips KA: Obesity and outcomes in premenopausal and postmenopausal breast cancer. Cancer Epidemiol Biomarkers Prev 14: 1686-1691, 2005.

9 Agresti R, Meneghini E, Baili P, Minicozzi P, Turco A, Cavallo I, Funaro F, Amash H, Berrino F, Tagliabue E and Sant M: Association of adiposity, dysmetabolisms, and inflammation with aggressive breast cancer subtypes: a cross-sectional study. Breast Cancer Res Treat 157: 179-189, 2016.

10 Tamimi RM, Colditz GA, Hazra A, Baer HJ, Hankinson SE, Rosner B, Marotti J, Connolly JL, Schnitt SJ and Collins LC: Traditional breast cancer risk factors in relation to molecular subtypes of breast cancer. Breast Cancer Res Treat 131: 159-167, 2012. 
11 Kwan ML, Kroenke CH, Sweeney C, Bernard PS, Weltzien EK, Castillo A, Factor RE, Maxfield KS, Stijleman IJ, Kushi LH, Quesenberry CP, Jr., Habel LA and Caan BJ: Association of high obesity with PAM50 breast cancer intrinsic subtypes and gene expression. BMC Cancer 15: 278, 2015.

12 Guy CT, Cardiff RD and Muller WJ: Induction of mammary tumors by expression of polyomavirus middle $\mathrm{T}$ oncogene: a transgenic mouse model for metastatic disease. Mol Cell Biol 12: 954-961, 1992.

13 Lin EY, Jones JG, Li P, Zhu L, Whitney KD, Muller WJ and Pollard JW: Progression to malignancy in the polyoma middle $\mathrm{T}$ oncoprotein mouse breast cancer model provides a reliable model for human diseases. Am J Pathol 163: 2113-2126, 2003.

14 Herschkowitz JI, Simin K, Weigman VJ, Mikaelian I, Usary J, $\mathrm{Hu}$ Z, Rasmussen KE, Jones LP, Assefnia S, Chandrasekharan S, Backlund MG, Yin Y, Khramtsov AI, Bastein R, Quackenbush J, Glazer RI, Brown PH, Green JE, Kopelovich L, Furth PA, Palazzo JP, Olopade OI, Bernard PS, Churchill GA, Van Dyke $\mathrm{T}$ and Perou CM: Identification of conserved gene expression features between murine mammary carcinoma models and human breast tumors. Genome Biol 8: R76, 2007.

15 Maglione JE, Moghanaki D, Young LJ, Manner CK, Ellies LG, Joseph SO, Nicholson B, Cardiff RD and MacLeod CL: Transgenic polyoma middle-T mice model premalignant mammary disease. Cancer Res 61: 8298-8305, 2001.

16 Rose DP, Connolly JM and Meschter CL: Effect of dietary fat on human breast cancer growth and lung metastasis in nude mice. J Natl Cancer Inst 83: 1491-1495, 1991.

17 Kimura Y and Sumiyoshi M: High-fat, high-sucrose, and highcholesterol diets accelerate tumor growth and metastasis in tumor-bearing mice. Nutr Cancer 59: 207-216, 2007.

18 Yan L and Sundaram S: Monocyte chemotactic protein-1 deficiency reduces spontaneous metastasis of Lewis lung carcinoma in mice fed a high-fat diet. Oncotarget 7: 24792-24799, 2016.

19 Yan L and DeMars LC: Effects of a high-fat diet on spontaneous metastasis of Lewis lung carcinoma in plasminogen activator inhibitor-1 deficient and wild-type mice. PLoS One 9: e110869, 2014.

20 Reeves PG, Nielsen FH and Fahey GCJ: AIN-93 purified diets for laboratory rodents: final report of the American Institute of Nutrition Ad Hoc Writing Committee on the reformulation of the AIN-76A rodent diet. J Nutr 123: 1939-1951, 1993.

21 Institute for Laboratory Animal Research: Guide for the Care and Use of Laboratory Animals. Washington, D.C.: National Academies Press, 2011.

22 Sundaram S, Freemerman AJ, Johnson AR, Milner JJ, McNaughton KK, Galanko JA, Bendt KM, Darr DB, Perou CM, Troester MA and Makowski L: Role of HGF in obesity-associated tumorigenesis: C3(1)-TAg mice as a model for human basal-like breast cancer. Breast Cancer Res Treat 142: 489-503, 2013.

23 Fidler IJ: General considerations for studies of experimental cancer metastasis. In: Methods in Cancer Research. Busch H (ed.). New York: Academic Press, pp. 399-439, 1978.

24 Welch DR, Neri A and Nicolson GL: Comparison of 'spontaneous' and 'experimental' metastasis using rat 13726 mammary adenocarcinoma metastatic cell clones. Invasion Metastasis 3: 65-80, 1983.

25 Ortega FJ, Moreno-Navarrete JM, Mayas D, Garcia-Santos E, Gomez-Serrano M, Rodriguez-Hermosa JI, Ruiz B, Ricart W, Tinahones FJ, Fruhbeck G, Peral B and Fernandez-Real JM:
Breast cancer 1 (BRCA1) may be behind decreased lipogenesis in adipose tissue from obese subjects. PLoS One 7: e33233, 2012.

26 Fang WB, Yao M, Jokar I, Alhakamy N, Berkland C, Chen J, Brantley-Sieders D and Cheng N: The CCL2 chemokine is a negative regulator of autophagy and necrosis in luminal B breast cancer cells. Breast Cancer Res Treat 150: 309-320, 2015.

27 Almholt K, Nielsen BS, Frandsen TL, Brunner N, Dano K and Johnsen $\mathrm{M}$ : Metastasis of transgenic breast cancer in plasminogen activator inhibitor-1 gene-deficient mice. Oncogene 22: 4389-4397, 2003.

28 Cowen S, McLaughlin SL, Hobbs G, Coad J, Martin KH, Olfert IM and Vona-Davis L: High-fat, high-calorie diet enhances mammary carcinogenesis and local inflammation in MMTVPyMT mouse model of breast cancer. Cancers 7: 1125-1142, 2015.

29 Witzel I, Milde-Langosch K, Schmidt M, Karn T, Becker S, Wirtz R, Rody A, Laakmann E, Schutze D, Janicke F and Muller $\mathrm{V}$ : Role of urokinase plasminogen activator and plasminogen activator inhibitor mRNA expression as prognostic factors in molecular subtypes of breast cancer. Onco Targets Ther 7: 22052213, 2014.

30 Buta M, Dzodic R, Durisic I, Markovic I, Vujasinovic T, Markicevic M and Nikolic-Vukosavljevic D: Potential clinical relevance of uPA and PAI-1 levels in node-negative, postmenopausal breast cancer patients bearing histological grade II tumors with ER/PR expression, during an early follow-up. Tumour Biol 36: 8193-8200, 2015.

31 Weitzenfeld P, Meron N, Leibovich-Rivkin T, Meshel T and Ben-Baruch A: Progression of luminal breast tumors is promoted by menage a trois between the inflammatory cytokine TNFalpha and the hormonal and growth-supporting arms of the tumor microenvironment. Mediators Inflamm 2013: 720536, 2013.

32 Dalamaga M, Sotiropoulos G, Karmaniolas K, Pelekanos N, Papadavid E and Lekka A: Serum resistin: a biomarker of breast cancer in postmenopausal women? Association with clinicopathological characteristics, tumor markers, inflammatory and metabolic parameters. Clin Biochem 46: 584-590, 2013.

33 Sternlicht MD, Dunning AM, Moore DH, Pharoah PD, Ginzinger DG, Chin K, Gray JW, Waldman FM, Ponder BA and Werb Z: Prognostic value of PAI1 in invasive breast cancer: evidence that tumor-specific factors are more important than genetic variation in regulating PAI1 expression. Cancer Epidemiol Biomarkers Prev 15: 2107-2114, 2006.

34 Lee YC, Chen YJ, Wu CC, Lo S, Hou MF and Yuan SS: Resistin expression in breast cancer tissue as a marker of prognosis and hormone therapy stratification. Gynecol Oncol 125: 742-750, 2012.

35 Gallego MI, Bierie B and Hennighausen L: Targeted expression of HGF/SF in mouse mammary epithelium leads to metastatic adenosquamous carcinomas through the activation of multiple signal transduction pathways. Oncogene 22: 8498-8508, 2003.

36 Yamashita J, Ogawa M, Yamashita S, Nomura K, Kuramoto M, Saishoji T and Shin S: Immunoreactive hepatocyte growth factor is a strong and independent predictor of recurrence and survival in human breast cancer. Cancer Res 54: 1630-1633, 1994.

37 Liu Y, Tamimi RM, Collins LC, Schnitt SJ, Gilmore HL, Connolly JL and Colditz GA: The association between vascular endothelial growth factor expression in invasive breast cancer and survival varies with intrinsic subtypes and use of adjuvant systemic therapy: results from the Nurses' Health Study. Breast Cancer Res Treat 129: 175-184, 2011. 
38 Brummer O, Athar S, Riethdorf L, Loning T and Herbst H: Matrix-metalloproteinases 1,2 , and 3 and their tissue inhibitors 1 and 2 in benign and malignant breast lesions: an in situ hybridization study. Virchows Arch 435: 566-573, 1999.

39 Schoeffner DJ, Matheny SL, Akahane T, Factor V, Berry A, Merlino $G$ and Thorgeirsson UP: VEGF contributes to mammary tumor growth in transgenic mice through paracrine and autocrine mechanisms. Lab Invest 85: 608-623, 2005.

40 Yoshiji H, Harris SR, Raso E, Gomez DE, Lindsay CK, Shibuya M, Sinha CC and Thorgeirsson UP: Mammary carcinoma cells over-expressing tissue inhibitor of metalloproteinases- 1 show enhanced vascular endothelial growth factor expression. Int J Cancer 75: 81-87, 1998.

41 Fenton JI, Nunez NP, Yakar S, Perkins SN, Hord NG and Hursting SD: Diet-induced adiposity alters the serum profile of inflammation in C57BL/6N mice as measured by antibody array. Diabetes Obes Metab 11: 343-354, 2009.

42 Yamauchi T, Kamon J, Waki H, Terauchi Y, Kubota N, Hara K, Mori Y, Ide T, Murakami K, Tsuboyama-Kasaoka N, Ezaki O, Akanuma Y, Gavrilova O, Vinson C, Reitman ML, Kagechika H, Shudo K, Yoda M, Nakano Y, Tobe K, Nagai R, Kimura S, Tomita M, Froguel P and Kadowaki T: The fat-derived hormone adiponectin reverses insulin resistance associated with both lipoatrophy and obesity. Nat Med 7: 941-946, 2001.

43 Rose DP, Gilhooly EM and Nixon DW: Adverse effects of obesity on breast cancer prognosis, and the biological actions of leptin. Int J Oncol 21: 1285-1292, 2002.

44 Mantzoros C, Petridou E, Dessypris N, Chavelas C, Dalamaga M, Alexe DM, Papadiamantis Y, Markopoulos C, Spanos E, Chrousos G and Trichopoulos D: Adiponectin and breast cancer risk. J Clin Endocrinol Metab 89: 1102-1107, 2004.
45 Macis D, Guerrieri-Gonzaga A and Gandini S: Circulating adiponectin and breast cancer risk: a systematic review and meta-analysis. Int J Epidemiol 43: 1226-1236, 2014.

46 Park J, Kusminski CM, Chua SC and Scherer PE: Leptin receptor signaling supports cancer cell metabolism through suppression of mitochondrial respiration in vivo. Am J Pathol 177: 3133-3144, 2010.

47 Lam JB, Chow KH, Xu A, Lam KS, Liu J, Wong NS, Moon RT, Shepherd PR, Cooper GJ and Wang Y: Adiponectin haploinsufficiency promotes mammary tumor development in MMTV-PyVT mice by modulation of phosphatase and tensin homolog activities. PLoS One 4: e4968, 2009.

48 Khandekar MJ, Cohen P and Spiegelman BM: Molecular mechanisms of cancer development in obesity. Nat Rev Cancer 11: 886-895, 2011.

49 Gordon RR, Hunter KW, La Merrill M, Sorensen P, Threadgill DW and Pomp D: Genotype $\mathrm{X}$ diet interactions in mice predisposed to mammary cancer: II. Tumors and metastasis. Mamm Genome 19: 179-189, 2008.

50 Garaulet M, Gomez-Abellan P, Alburquerque-Bejar JJ, Lee YC, Ordovas JM and Scheer FA: Timing of food intake predicts weight loss effectiveness. Int J Obes 37: 604-611, 2013.

Received August 23, 2016

Revised September 27, 2016

Accepted September 29, 2016 